\title{
Actinomycetales Infection
}

National Cancer Institute

\section{Source}

National Cancer Institute. Actinomycetales Infection. NCI Thesaurus. Code C84534.

An infectious process caused by actinomycetales which is an order of Actinobacteria. 